\title{
Uso de Dados de Radar Meteorológico em Modelo Hidrológico SCS-CN para a Estimativa de Escoamento Superficial
}

\author{
Use of Weather Radar Data in a SCS-CN Hydrological Model to Estimate Surface Runoff
}

Bárbara Hass Miguel ${ }^{1}$ e Camilo Daleles Rennó ${ }^{2}$

1 Universidade de Brasília, Instituto de Geociências, Brasília-DF, Brasil. babs.hass@ gmail.com

ORCID: https://orcid.org/0000-0003-3402-5604

2 Instituto Nacional de Pesquisas Espaciais, Departamento de Processamento de Imagens, São José dos Campos-SP, Brasil.

camilo@dpi.inpe.br

ORCID: https://orcid.org/0000-0001-9920-4473

Resumo: O objetivo do presente trabalho foi avaliar a viabilidade do uso de estimativas de chuva a partir de dados do radar meteorológico do Instituto de Pesquisas Meteorológicas de Bauru (IPMet/UNESP) na implementação do modelo hidrológico distribuído simplificado Soil Conservation Service - Curve Number (SCS-CN), a fim de se analisar o escoamento superficial de eventos de precipitação na bacia hidrográfica do Rio Jacaré-Guaçu, localizada na região centro-leste do estado de São Paulo. Nesse trabalho, as estimativas de chuva a partir de dados do radar meteorológico do IPMet foram calibradas com dados de 18 estações pluviométricas, contudo, a área de estudo apresenta apenas uma estação fluviométrica em operação, localizada no exutório da bacia. Foram escolhidos dois eventos ocorridos em janeiro e fevereiro de 2013, de acordo com a propagação do escoamento superficial extraído a partir da aplicação de um filtro digital de separação de escoamento. Os resultados foram satisfatórios em relação a propagação do escoamento superficial gerada pelo modelo hidrológico SCS-CN. Entretanto, é preciso ressaltar que alguns fatores de incerteza foram levados em consideração no processo de implementação do modelo hidrológico. Um desses fatores é que a falta de calibração de parâmetros do modelo SCS-CN, como os valores tabelados da CN, pode ter produzido alguns valores espúrios de chuva efetiva e, consequentemente, isso pode ter interferido nos valores de propagação do escoamento superficial.

Palavras-chave: Modelo hidrológico SCS-CN. Radar meteorológico. Chuva efetiva. Bacia hidrográfica.

\begin{abstract}
The aim of the present work was to evaluate the feasibility of using rain based on meteorological radar data from the Institute of Meteorological Research of Bauru (IPMet / UNESP) in the implementation of the simplified distributed hydrological model Soil Conservation Service - Curve Number (SCS) - CN), an end of analysis or runoff of events in the Jacaré-Guaçu River watershed, located in the central-eastern region of the São Paulo State. In this work, how to display rain from IPMet weather radar data was calibrated with data from 18 rainfall stations, however, a study area has only one fluviometric station in operation, located outside the basin. Two events that took place in January and February 2013 were selected, according to the spread runoff extracted from the application of a digital runoff selection filter. The results were satisfactory about the propagation of runoff generated by the hydrological model SCS-CN. However, it should be noted that some factors of uncertainty were taken into account in the process of implementing the hydrological model. One of these factors is the lack of calibration of the parameters of the SCS$\mathrm{CN}$ model, such as the tabulated values of the $\mathrm{CN}$, which may produce some spurious data of the effective rain and, consequently, this may have interfered with the values of propagation of the runoff.
\end{abstract}

Keywords: SCS-CN Hydrological Model. Weather radar. Effective rainfall. Watershed.

\section{INTRODUÇÃO}

As transformações dos centros urbanos em áreas com altas densidades populacionais e as atividades humanas que degradam a vegetação natural apresentam efeitos negativos que são refletidos diretamente sobre o sistema de drenagem das bacias hidrográficas (ZHANG et al., 2017). A existência de áreas altamente impermeabilizadas traz como consequência o aumento do volume escoado superficialmente, pois grande parte da água das chuvas não consegue penetrar no solo impermeabilizado. Esse escoamento superficial geralmente ocorre de forma muito abundante e rápida, criando vazões nos cursos d'água extremamente altas durante e 
imediatamente após as chuvas, formando as enchentes (BEVEN, 2012).

No Brasil, ainda existe uma grande escassez em relação a estudos e registros de dados para monitorar com mais precisão o regime pluviométrico e, sobretudo, a frequência desses eventos sobre uma determinada região (FAN; RAMOS; COLLISCHONN, 2015). A falta de dados consistentes sobre o regime hidrológico e a complexidade desses sistemas são os principais problemas enfrentados durante a análise e avaliação da distribuição espacial e temporal da precipitação nas bacias hidrográficas. Nesse contexto, os modelos hidrológicos são fundamentais para o estudo de monitoramento de enchentes e análise do sistema de drenagem de uma bacia hidrográfica (BEVEN, 2012; EMMANUEL et al., 2015).

A simulação hidrológica tem como princípio desenvolver modelos que representem os processos e os mecanismos hidrológicos em uma bacia (BEVEN, 2012). Um importante modelo utilizado na simulação hidrológica é o que simula a transformação da chuva em vazão direta. Eles são utilizados para simular processos hidrológicos, principalmente, no que se refere à dinâmica dos escoamentos na seção exutória da bacia (ASCE, 1996; BEVEN 2012). Esses modelos permitem simular cenários futuros de uso e ocupação das bacias, o que auxilia os tomadores de decisão em suas ações no planejamento e desenvolvimento.

A precipitação é a principal condição de contorno desses modelos e, como parte fundamental do ciclo hidrológico, tem características próprias de ocorrência de acordo com a localização, intensidade e variabilidade espaço-temporal. A chuva é a forma mais comum de precipitação, que depende do tipo de nuvem precipitante, estratiforme ou convectiva, sendo assim, a sua distribuição espacial pode variar consideravelmente em extensão horizontal. No entanto, as medidas pluviométricas são feitas apenas em alguns pontos do terreno, resultando numa baixa densidade de medidas, principalmente em áreas mais remotas (EMMANUEL et al., 2015; MISHRA et al., 2018; POTDAR et al., 2019).

Com o avanço de tecnologias de sensoriamento remoto como o uso de satélites e radares, houve a possibilidade do desenvolvimento de instrumentos voltados para a análise da distribuição espacial e temporal da chuva como os radares meteorológicos. Os dados provenientes de radar podem fornecer, em intervalos de poucos minutos, informações da precipitação de forma espacializada, com resolução espacial média de $1 \mathrm{~km}$, dependendo da medida que o feixe se afasta do radar (RAGHAVAN, 2013; PRICE et al., 2014). Esse instrumento é um sensor micro-ondas ativo colocado em torres, plataformas aéreas ou espaciais que emite pulsos de energia eletromagnética em intervalos de tempo regulares, concentrados em um feixe de pequena abertura através de uma antena rotativa. A fração da energia que retorna ao radar é medida pelo receptor e, conhecendo-se o intervalo de tempo entre a emissão e o retorno do eco, é possível estimar a precipitação (THORNDAHL et al., 2017).

No âmbito da hidrologia, diversos estudos implementaram modelos hidrológicos a partir da integração de dados de radar com a rede pluviométrica. Um dos modelos mais conhecidos e utilizado é o modelo hidrológico distribuído simplificado Soil Conservation Service - Curve Number (SCS-CN) (MOORE, 2008; FAN; COLLISCHONN, 2014; CABRAL; SAKURAGI; SILVEIRA., 2017; POTDAR et al., 2019). Segundo Beven (2012), o modelo SCS-CN apresenta algumas vantagens: é consistente; computacionalmente eficiente; os dados de entrada necessários são geralmente disponíveis e relaciona o escoamento superficial com o tipo, o uso e a cobertura do solo.

Nesse contexto, o objetivo do presente trabalho é avaliar a viabilidade do uso de estimativas de chuva a partir de dados do radar meteorológico do Instituto de Pesquisas Meteorológicas de Bauru (IPMet/UNESP) na implementação do modelo hidrológico SCS-CN, a fim de se analisar o escoamento superficial de alguns eventos de precipitação na bacia hidrográfica do Rio Jacaré-Guaçu, localizada no Estado de São Paulo. Essa bacia foi escolhida pois encontra-se nas limitações do raio de abrangência do radar do IPMet.

\section{MATERIAIS E MÉTODOS}

\section{1 Área de estudo}

A área de estudo compreende na Bacia Hidrográfica do Rio Jacaré Guaçu, localizada no centro-leste do Estado de São Paulo, entre os paralelos $21^{\circ} 37^{\prime}$ e $22^{\circ} 22^{\prime}$ de latitude sul e os meridianos $47^{\circ} 43^{\prime}$ e $48^{\circ} 56^{\prime}$ de longitude oeste. A bacia abrange os municípios de Araraquara, São Carlos, Ibaté e Itirapina, totalizando 
uma área de $1.820 \mathrm{~km}^{2}$.

Para este estudo foram considerados dois instrumentos de medida de chuva: pluviômetros e radar meteorológico. A fonte de dados de radar é o IPMet da Universidade Estadual Paulista (Unesp) de Bauru e os dados pluviométricos são da Agência Nacional de Águas (ANA) e do Departamento de Água e Energia Elétrica do Estado de São Paulo (DAEE). Foram identificadas as estações existentes no raio de abrangência quantitativa do radar de $150 \mathrm{~km}$ e da bacia do Rio Jacaré-Guaçu (Figura 1).

Figura 1 - Representação da localização da bacia hidrográfica do rio Jacaré Guaçu e do radar meteorológico do IPMet em Bauru.

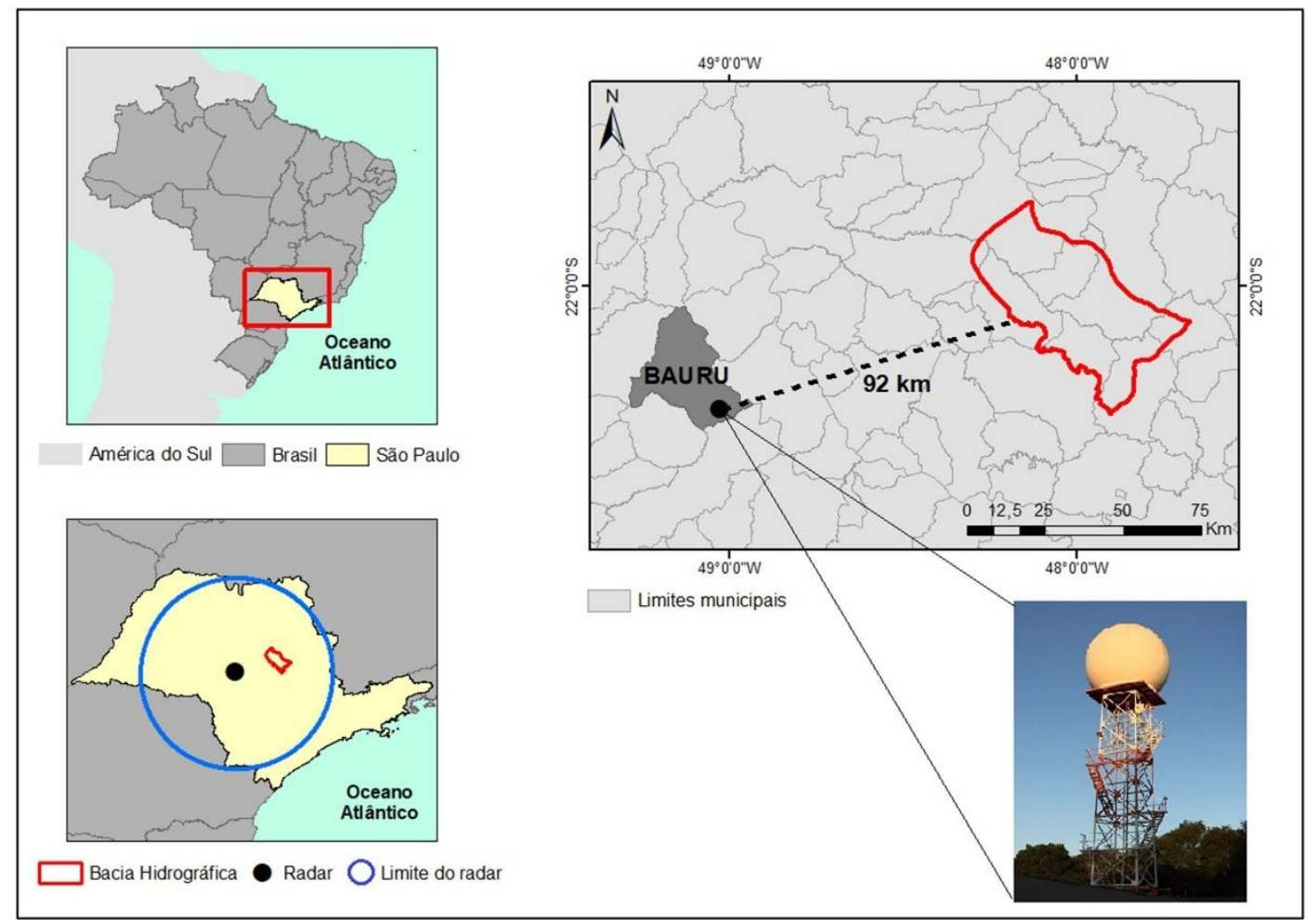

Fonte: Os autores (2020).

\subsection{Dados Hidrometeorológicos}

Nesse trabalho, as estimativas de chuva do radar meteorológico do IPMet foram calibradas com dados de 18 estações pluviométricas, contudo, a área de estudo apresenta apenas uma estação fluviométrica em operação, localizada no exutório da bacia, portanto, todos os dados de vazão são provenientes da mesma estação fluviométrica (Figura 2). Os pluviômetros utilizados pela ANA e DAEE são do tipo Ville de Paris (ANA, 2014). Já a estação fluviométrica, operada pelo DAEE, registra a vazão por meio de leituras a partir de uma régua linimétrica. 
Figura 2 - Mapa de localização das estações pluviométricas e fluviométrica utilizadas neste estudo.

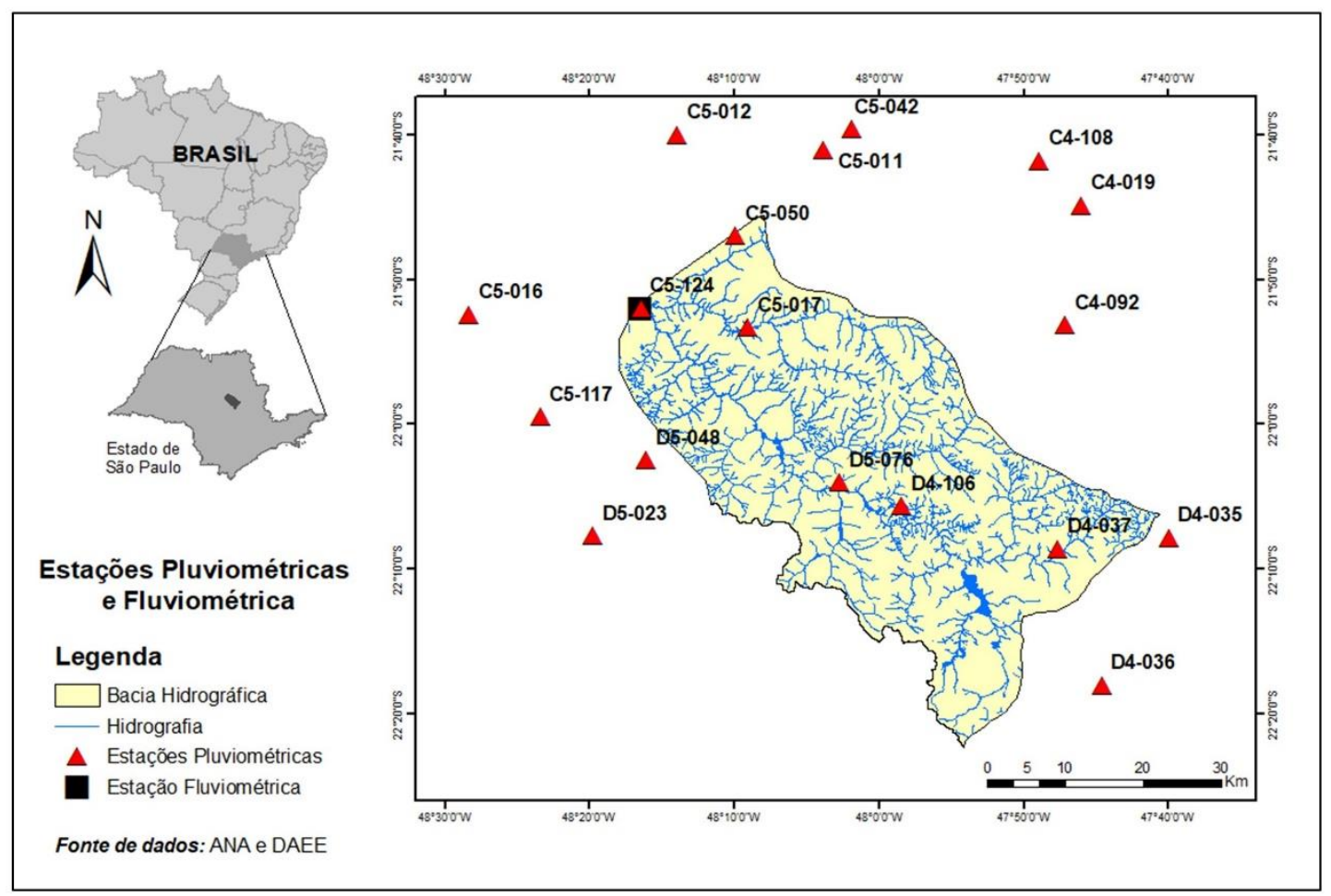

Fonte: Os autores (2020).

Os dados do radar meteorológico do IPMet utilizados nesse estudo foram fornecidos em formato CAPPI (Constant Altitude Plan Position Indicator) com altura de 3,5 km (altura padrão), amostrados a cada 7,5 minutos, durante o período de janeiro a dezembro de 2013. Esses arquivos referentes a refletividade da chuva foram convertidos para taxa de precipitação por meio da relação de Marshall e Palmer (1942), conforme a Eq. (1):

$$
Z=200 R^{1,6}
$$

onde $\mathrm{Z}$ é a refletividade da chuva (dBZ) e R é a taxa de precipitação $(\mathrm{mm} / \mathrm{h})$.

Para a quantificação do acumulado de chuva, os dados foram integrados em períodos diários ( 24 horas), gerando matrizes com resolução espacial de $1 \mathrm{~km}$ x $1 \mathrm{~km}$ (IPMET, 2020). O horário de acumulação da chuva com radar iniciou-se às 07:00h de modo a acompanhar o horário de medição dos pluviômetros. Em seguida, esses dados foram calibrados com a chuva registada pelos postos pluviométricos a partir do Método de polígonos de Thiessen (1911).

\subsection{Seleção dos eventos de escoamento superficial}

A escolha dos eventos avaliados nesse trabalho foi a partir da propagação do escoamento superficial extraído por meio da aplicação de um filtro digital numérico de separação de escoamento. Esses filtros são algoritmos utilizados para calcular o fluxo de base de cursos d'água, a partir de dados de vazão, supondo a separação da vazão de um rio em duas componentes (escoamento superficial e de base), automatizando o processo de separação de escoamento. Para esse trabalho, a avaliação do modelo hidrológico foi realizada através da comparação dos hidrogramas gerados pelo modelo com os hidrogramas observados pelo filtro de Eckhardt (2005) para cada evento selecionado.

Em seu estudo, Eckhardt demonstrou que outros filtros publicados previamente poderiam ser representados de acordo com a Eq. (2):

$$
b_{i}=\frac{\left(1-B F I_{\max }\right) x b_{i-1}+(1-x) B F I_{\max } Q_{i}}{1-x \cdot B F I_{\max }}
$$


onde $Q$ é a vazão total, $x$ representa o decaimento exponencial do período de recessão e $B F I_{\text {max }}$ é o índice de fluxo de base máximo, sendo que este parâmetro está relacionado a características geológicas e de cobertura do solo. Para este estudo, foi considerado $B F I_{\max }=0,80$.

No presente trabalho, foram escolhidos dois eventos que apresentaram escoamento superficial mais acentuados, conforme descritos na Figura 3.

Figura 3 - Escoamento superficial após a aplicação do Filtro de Eckhardt e eventos selecionados para análise.

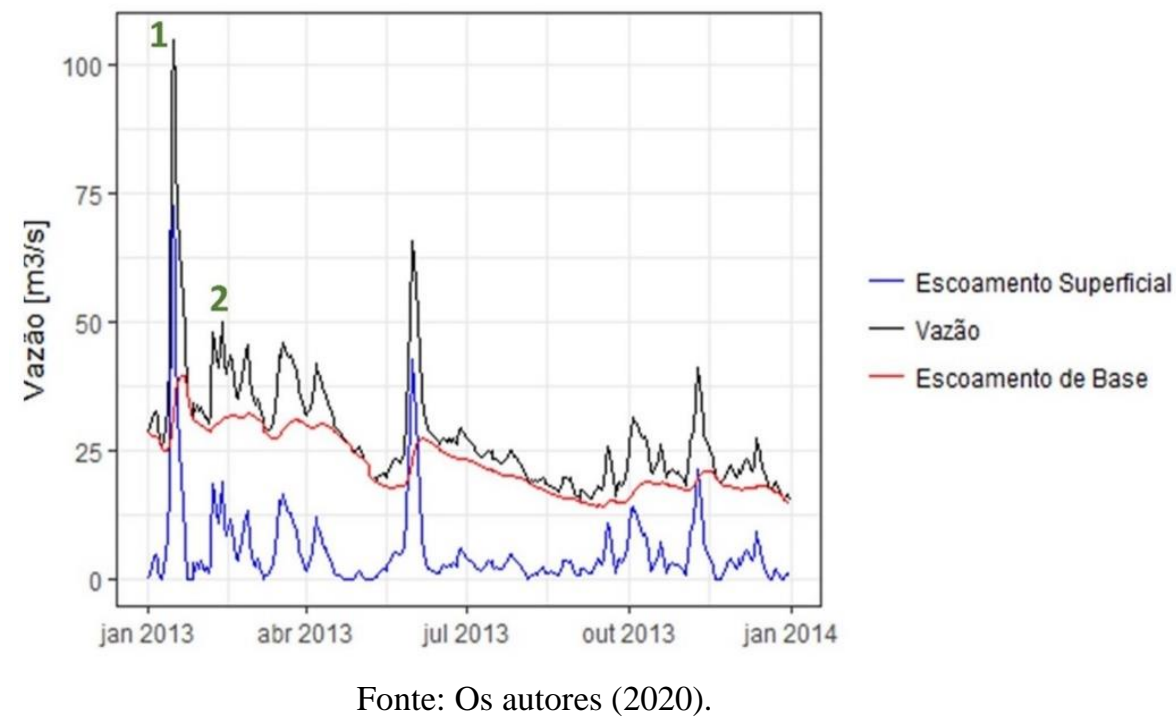

\subsection{Modelo SCS-CN}

As etapas referentes à implementação do modelo hidrológico SCS-CN estão resumidas na Figura 4.

Figura 4 - Fluxograma do Modelo Hidrológico SCS-CN.

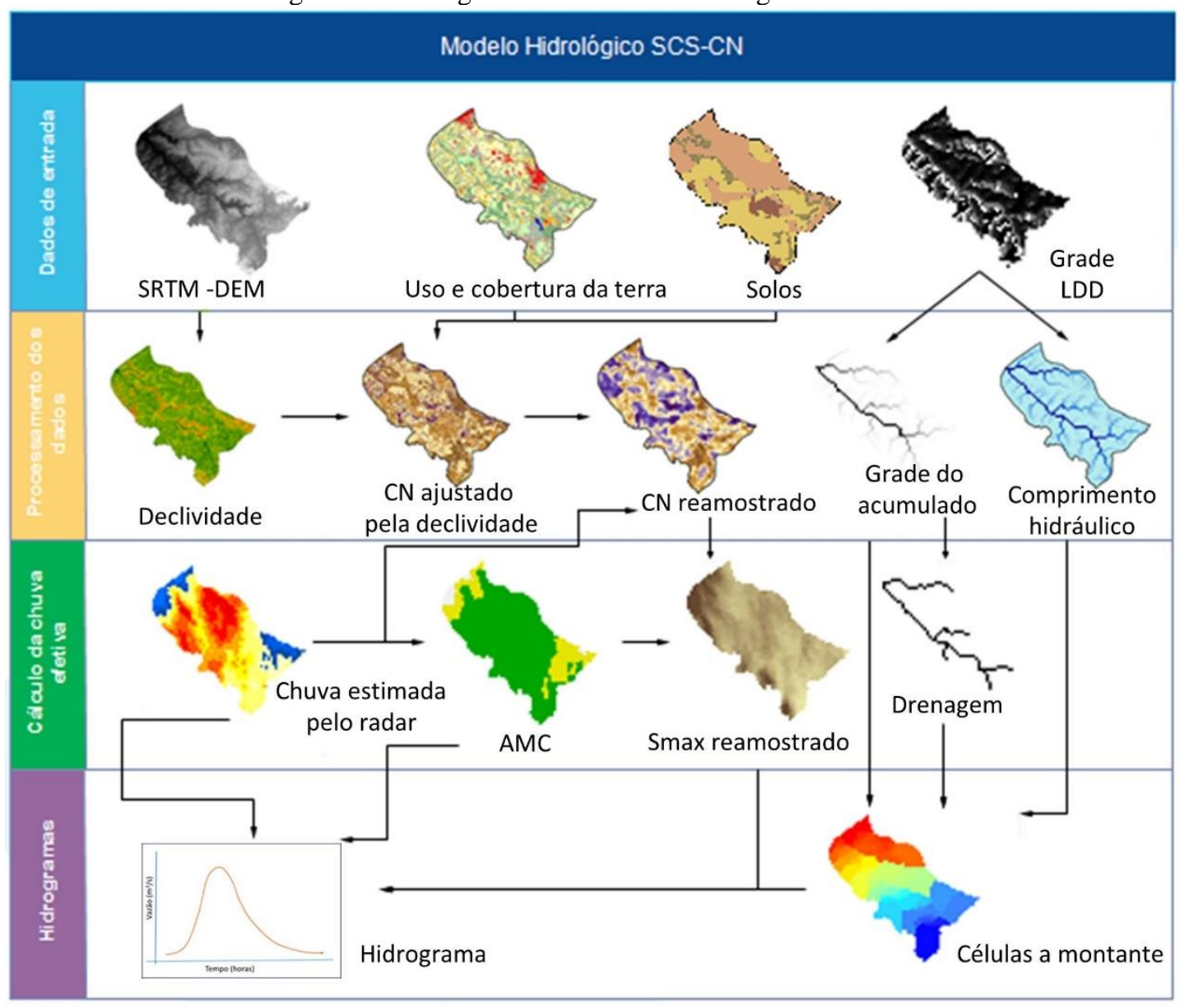

Fonte: Os autores (2020). 
O modelo SCS-CN foi originalmente desenvolvido na década de 1950, a fim de estimar a transformação direta da precipitação em escoamento superficial (SCS, 1956; MISHRA; SINGH, 2004). Esse modelo hidrológico baseia-se no conceito de que a lâmina de escoamento superficial produzida em um dado evento é uma função da altura total da lâmina precipitada e de um parâmetro Curva Número $(C N)$, que representa as perdas que ocorrem, principalmente, devido à infiltração, à interceptação vegetal e à retenção em depressões do terreno (PEREIRA, 2009).

Para o modelo SCS-CN, a geração de escoamento $(Q)$ em milímetros é definida pela entrada de chuva $(P)$; um parâmetro $(\lambda)$, que está relacionado à absorção inicial da chuva $(I)$ antes que a mesma infiltre ou escoe no terreno e o parâmetro de retenção máxima $\left(S_{\max }\right)$, conforme a Eq. (3):

$$
I=\lambda S_{\max }
$$

A absorção inicial da chuva também considera a evapotranspiração e a interceptação no balanço hídrico do solo (BEVEN, 2012). Assim tem-se a Eq. (4):

$$
\left\{\begin{array}{l}
Q=\frac{\left(P-\lambda S_{\max }\right)^{2}}{\left(P-\lambda S_{\max }\right)+S_{\max }} \text { se } P>I \\
Q=0 \quad \text { caso contrário }
\end{array}\right.
$$

onde $\lambda$ é um valor constante comumente utilizado como 0,2 (ASCE, 1996).

Por meio do valor de $C N$ é possível determinar $S_{\text {max }}$ em milímetros de acordo com a Eq. (5):

$$
S_{\max }=\left(\frac{100}{C N}-1\right) 254
$$

onde $C N$ é um valor tabelado em função do uso e cobertura da terra, tipo e condição hidrológica do solo.

A classificação do grupo hidrológico do solo proposta para os solos brasileiros de Sartori, Genovez e Lombardi Neto (2005) é apresentada no Quadro 1. Essa classificação leva em consideração a profundidade, a textura, o gradiente textural, a porosidade dos solos e a atividade da argila.

Quadro 1 - Classificação dos grupos hidrológicos e suas características.

\begin{tabular}{|l|l|}
\hline \multicolumn{1}{|c|}{ Grupos Hidrológicos } & \multicolumn{1}{c|}{ Características } \\
\hline A & Solos arenosos, profundos e bem drenados. \\
\hline B & Solos arenosos com pouca argila e solo orgânico. \\
\hline C & Solos mais argilosos que aqueles do grupo B, com baixa permeabilidade. \\
\hline D & Solos com argilas pesadas, muito impermeáveis. \\
\hline
\end{tabular}

Fonte: Adaptado de Sartori, Genovez e Lombardi Neto (2005).

A aplicação do $C N$ leva em consideração a condição média de umidade antecedente do solo, chamada de Antecedent Moisture Condition (AMC). Esta condição considera os eventos chuvosos ocorridos nos cinco dias anteriores ao dia analisado. São três as condições AMC consideradas:

AMC 1 - Situação em que os solos estão secos. Tucci (2002) sugere que para a superfície atingir esta condição, a precipitação acumulada dos cinco dias anteriores deve ser menor que $36 \mathrm{~mm}$;

AMC 2 - Situação média em que os solos correspondem à umidade de capacidade de campo;

AMC 3 - Situação em que ocorreram precipitações consideráveis nos últimos cinco dias e o solo encontra-se saturado. Nesta condição, a precipitação acumulada nos cinco dias anteriores deve ser maior que $53 \mathrm{~mm}$, segundo Tucci (2002).

Os valores de $C N$ encontrados nas tabelas do SCS correspondem ao valor para a situação média, AMC $2\left(C N_{2}\right)$. As correções para as situações $1\left(C N_{1}\right)$ e $3\left(C N_{3}\right)$ são calculadas em função do valor de $C N_{2}$ por (ARNOLD; WILLIAMS, 1995), de acordo com a Eq. (6): 


$$
C N_{1}=C N_{2}-\frac{20\left(100-C N_{2}\right)}{100-C N_{2}+\exp \left[2,533-0,0636\left(100-C N_{2}\right)\right]}
$$

E para a condição AMC $3\left(C N_{3}\right)$ tem-se a Eq. (7):

$$
C N_{3}=C N_{2} \exp \left[0,00673\left(100-C N_{2}\right)\right]
$$

Os valores tabelados de $C N_{2}$ são estabelecidos para uma bacia com declividade média de 5\%. Arnold e Williams (1995) propõem um ajuste deste valor para outras declividades por meio da Eq. (8):

$$
C N_{2 S}=\frac{1}{3}\left(C N_{3}-C N_{2}\right)[1-2 \exp (-13,86 \theta)]+C N_{2}
$$

onde $\theta$ é a declividade média da bacia em porcentagem (\%).

Após o cálculo de $C N_{2 S}$, as correções de $C N_{1}$ e $C N_{3}$ pelas Eq. (6) e (7) devem ser feitas substituindose o valor de $C N_{2}$ por $C N_{2 S}$.

\subsubsection{DADOS DE ENTRADA}

Para esse estudo, foi utilizado o Modelo Digital de Terreno (DEM) SRTM (Shuttle Radar Topography Mission) de $30 \mathrm{~m}$ de resolução (1 arco segundo). Utilizou-se o DEM para definir a direção preferencial do fluxo nas vertentes, conhecido como Local Drain Direction (LDD), da extração da drenagem, do cálculo do comprimento hidráulico e da declividade (RENNÓ et al., 2008; ROSIM et al., 2013).

O mapa pedológico do Estado de São Paulo, desenvolvido por Oliveira et al. (1999) foi utilizado como base para a classificação dos grupos hidrológicos da bacia. Já o mapa de uso e cobertura da bacia foi gerado por meio de uma classificação supervisionada pelo método da Máxima Verossimilhança (Maxver) em uma imagem do satélite Landsat 8/OLI (órbita 220, ponto:075) do dia 17 de abril de 2013. Esse classificador foi utilizado pois é considerado o método mais preciso entre os classificadores "pixel a pixel", levando em consideração a variância das classes. Para obter uma resolução espacial maior das bandas espectrais do sensor OLI (bandas 1 a 7, resolução de $30 \mathrm{~m}$ ), executou-se a fusão com a banda pancromática (banda 8 , resolução de $15 \mathrm{~m}$ ) pelo método Gram-Schmidt, obtendo-se bandas multiespectrais com 15m de resolução espacial (TSO; MATHER, 2009).

Na etapa de treinamento, foi gerada uma composição colorida R5G4B3, sobre a qual foram extraídas amostras manualmente da imagem fusionada para realização da classificação. Previamente foram selecionados 7 tipos de uso: área urbana, culturas agrícolas, água, campo/pastagem, floresta, reflorestamento e solo exposto. Na etapa de validação, imagens do satélite RapidEye foram utilizadas como referência. Foi realizado um mosaico de 11 cenas do satélite Rapideye datadas de novembro e dezembro de 2012, na composição de bandas R5G4B3, realçando a vegetação. Os pontos de validação foram amostrados por meio de uma amostragem aleatória estratificada. A estratificação foi realizada a partir das classes de uso e cobertura da terra, sendo amostrados um total de 1500 pontos. O número de pontos foi definido de acordo com o tamanho das classes, sendo que foram amostrados 200 pontos para a classe água, 200 pontos para a classe área urbana, 300 pontos para a classe cultura agrícola, 200 pontos para a classe floresta, 150 pontos para a classe campo, 250 pontos para a classe solo exposto e 200 para a classe reflorestamento.

\subsubsection{PROCESSAMENTO DOS DADOS}

Os valores de $C N$ foram definidos pela intersecção do uso e cobertura da terra e do mapa de solos, descritos no Quadro 2. A condição hidrológica do solo está relacionada à cobertura da terra, como densidade da cobertura vegetal e rugosidade do terreno (USDA,1986). 
Quadro 2 - Curva número $(\mathrm{CN})$ para diferentes tipos de uso e cobertura da terra, condição hidrológica e grupo hidrológico do solo.

\begin{tabular}{|c|c|c|}
\hline Uso e cobertura da Terra & Condição Hidrológica & $\begin{array}{c}\text { Grupo hidrológico do solo } \\
\text { A B C D }\end{array}$ \\
\hline Água & - & $-\quad-\quad-100$ \\
\hline Área urbana & Pobre & 89929495 \\
\hline Culturas Agrícolas & Boa & 61738184 \\
\hline Florestas & Boa & 25557077 \\
\hline Pastagens & Média & 49697984 \\
\hline Solo Exposto & Pobre & 77869194 \\
\hline Reflorestamento & Média & 36607379 \\
\hline
\end{tabular}

Fonte: Adaptado de USDA (1986) e Beven (2012).

Esses valores foram corrigidos pela declividade, segundo a Eq. (8) e de acordo com a respectiva AMC. Os dados de entrada de chuva foram as estimativas de chuva a partir do radar, o que representa o acumulado de chuva diário em milímetro $(\mathrm{mm})$. Até o cálculo do $S_{\max }$, todas as etapas foram realizadas com uma resolução espacial de $30 \mathrm{~m}$, porém, no momento da entrada do dado de chuva, o $S_{\text {max }}$ foi reamostrado para a resolução espacial do radar de $1 \mathrm{~km}$ por meio da média zonal. Isso foi feito com intuito de manter os valores das estimativas de chuva do radar meteorológico inalterados, pois, caso contrário, haveria a inclusão de mais uma fonte de incerteza. A calibração do parâmetro $\lambda$ foi realizada para cada evento separadamente, pois além de variar em função da bacia, a constante $\lambda$ também varia em função da intensidade da precipitação (WOODWARD et al., 2003).

Fez-se necessário calcular o valor de $C N$ médio e a declividade média da área à montante de cada célula. Para este cálculo, foi necessário utilizar os valores da grade acumulada gerada através do LDD para acumular os valores de $\mathrm{CN}$ e de declividade a montante. A soma de valores acumulados ao longo da bacia deve ser feita em uma ordem específica, de modo a acumular os valores de interesse. A trajetória é definida pela ordem da grade acumulada, ou seja, dos menores para os maiores valores. Os valores acumulados são divididos pelo total de células à montante para o cálculo do $C N$ médio e declividade média. Todas as etapas do modelo SCS-CN desse estudo foram implementadas e processadas em linguagem R, no software R Studio, utilizando os pacotes Raster e Rgdal (MIGUEL, 2018).

\subsubsection{CÁlCULO DA CHUVA EFETIVA E HIDROGRAMA}

Junto ao modelo de geração de escoamento SCS-CN, geralmente utiliza-se o modelo do hidrograma unitário para a propagação do escoamento superficial. Segundo Chow, Maidment e Mays (1988) e ASCE (1996), o hidrograma triangular é definido pelos seguintes parâmetros: tempo de pico $\left(T_{p}\right)$, tempo de base $\left(T_{b}\right)$, tempo de concentração $\left(T_{c}\right)$ e vazão de pico $\left(Q_{p}\right)$.

O tempo de pico $\left(T_{p}\right)$ é definido pelo tempo entre o início do evento de chuva e a vazão de pico, sendo expresso pelo tempo de retardo $\left(T_{L}\right)$ e pela duração do evento de chuva $(\Delta t)$ em (h), conforme a Eq. (9):

$$
T_{p}=T_{L}+\frac{\Delta t}{2}
$$

O tempo de retardo $\left(T_{L}\right)$ é definido pelo tempo entre o centro de massa da chuva efetiva e da vazão de pico, formulado como segue a Eq. (10) (ASCE, 1996):

$$
T_{L}=\frac{1,347 L_{h}^{0,8}\left(S_{\max }+2,54\right)^{0,7}}{1900 \theta^{0,5}}
$$

onde $L_{h}$ é o comprimento hidráulico da bacia (m); $S_{\max }$ é a capacidade máxima de armazenamento do solo $(\mathrm{cm})$ e $\theta$ é a declividade média da bacia em porcentagem (\%).

De posse de $T_{p}$, é possível calcular o tempo de base $\left(T_{b}\right)$, sendo o tempo correspondente à contribuição do escoamento superficial no hidrograma de uma bacia, definido por ASCE (1996) de acordo com a Eq. (11): 


$$
T_{b}=(2,67094) T_{p}
$$

O tempo de concentração é obtido por meio da velocidade $(V)$ e do comprimento $(L)$ conforme a Eq. (12):

$$
T_{c}=\frac{L}{V}
$$

A velocidade $(V)$ pode ser calculada pela Eq. (13):

$$
V=k \theta^{0,5}
$$

onde $k$ é o coeficiente de simplificação, obtido de acordo com o tipo de cobertura do solo, resumido pelo Quadro 3 da SCS de 1956.

Quadro 3 - Valores de coeficiente $k$ em relação aos usos da terra e regime de escoamento.

\begin{tabular}{|l|c|}
\hline \multicolumn{1}{|c|}{ Uso da terra e regime de escoamento } & Coeficiente k \\
\hline Floresta com muita folhagem no solo & 0,76 \\
\hline Área com pouco cultivo & 1,52 \\
\hline Pasto ou grama baixa & 2,13 \\
\hline Áreas cultivadas & 2,74 \\
\hline Solo quase sem cultivo & 3,05 \\
\hline Caminhos de escoamento em grama, pasto & 4,57 \\
\hline Superfície pavimentada & 6,10 \\
\hline
\end{tabular}

Fonte: SCS (1956).

Segundo ASCE (1996), a vazão de pico $\left(Q_{p}\right)$ em $\left(\mathrm{m}^{3} / \mathrm{s}\right)$ é definida pela área de drenagem $(A) \mathrm{em}\left(\mathrm{km}^{2}\right)$; pela precipitação efetiva $(Q)$ em $(\mathrm{cm})$ e pelo tempo de pico $\left(T_{p}\right)$ em $(\mathrm{h})$, segundo a Eq. (14):

$$
Q_{p}=\frac{(2,08073241781107) A Q}{T_{p}}
$$

\section{RESULTADOS E DISCUSSÕES}

\subsection{Classificação do uso e cobertura da terra}

A bacia do Rio Jacaré-Guaçu pode ser classificada como uma bacia predominantemente agrícola (Figura 5). Com relação às atividades antrópicas, verificou-se predominantemente a presença da agropecuária, dividida em áreas agrícolas, pastagem e solo exposto (dominantemente em fase de preparo para o cultivo da cana-deaçúcar e citricultura), somando aproximadamente $70 \%$ de toda a área da bacia. A exatidão global da classificação do uso e cobertura da terra foi de $88 \%$, considerada muito boa.

Apesar da existência de alguns fragmentos de vegetação nativa, representados por Áreas de Preservação Permanente (APPs), a proteção dos recursos hídricos frente às atividades humanas não é efetiva, devido à descontinuidade desses fragmentos na bacia. 
Figura 5 - Mapa do uso e cobertura da terra da bacia.

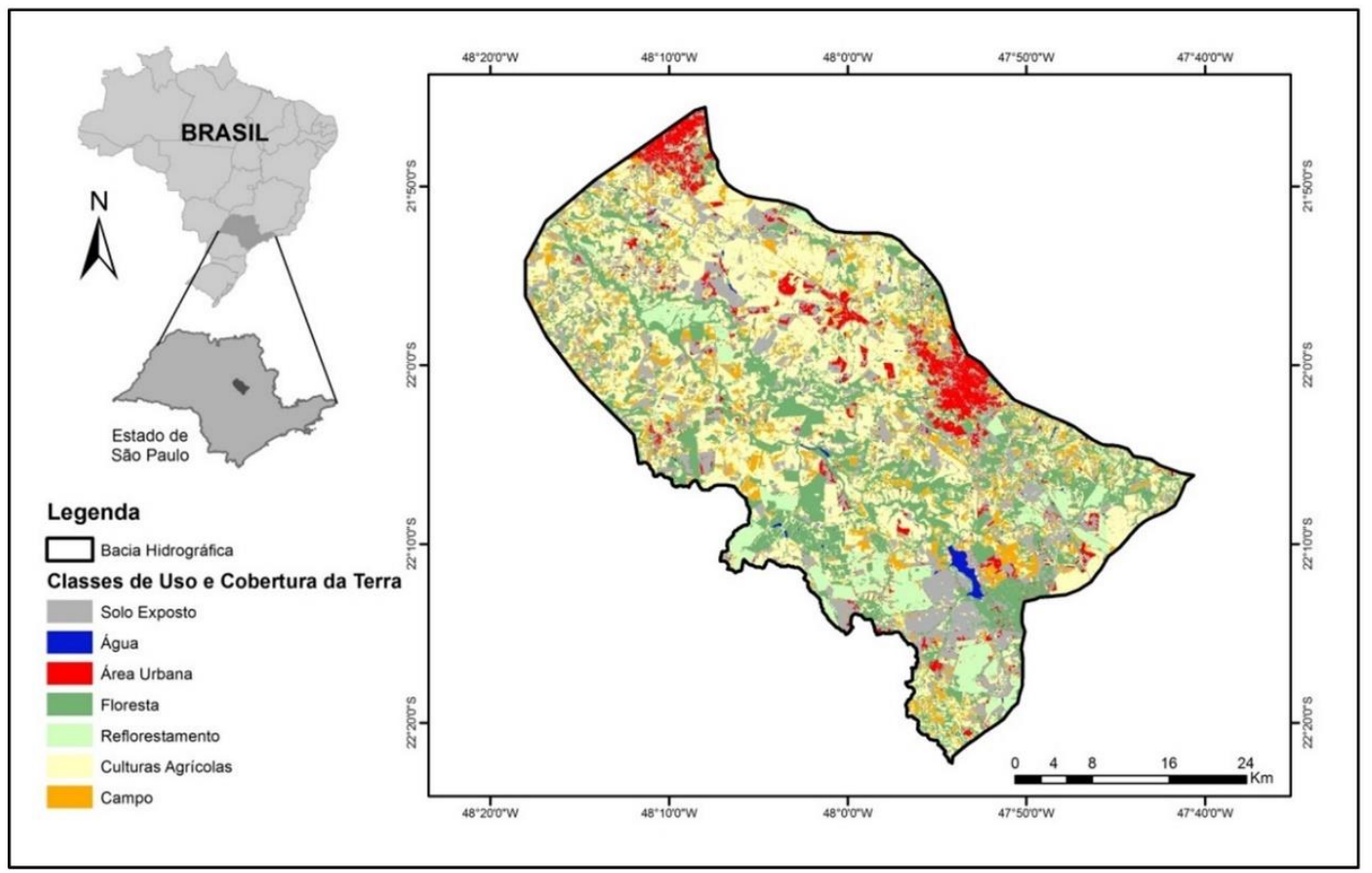

Fonte: Os autores (2020).

\subsection{Modelagem hidrológica}

A Figura 6 apresenta os valores de $C N$ corrigidos pela declividade para a bacia do Rio Jacaré Guaçu. A bacia apresentou valores altos de $C N$ nas regiões de vale devido a predominância de áreas relacionadas à agricultura, como a cana-de-açúcar, citricultura e de solo exposto. Valores mais altos da $C N$ também foram encontrados próximo do exutório, devido à localização da mancha urbana do município de Araraquara, e na região da cabeceira, onde a geomorfologia de planaltos e colinas favorece o predomínio da silvicultura.

Figura 6 - Mapa de CNs corrigidas pela declividade. Uma $C N$ maior representa maior geração de escoamento.

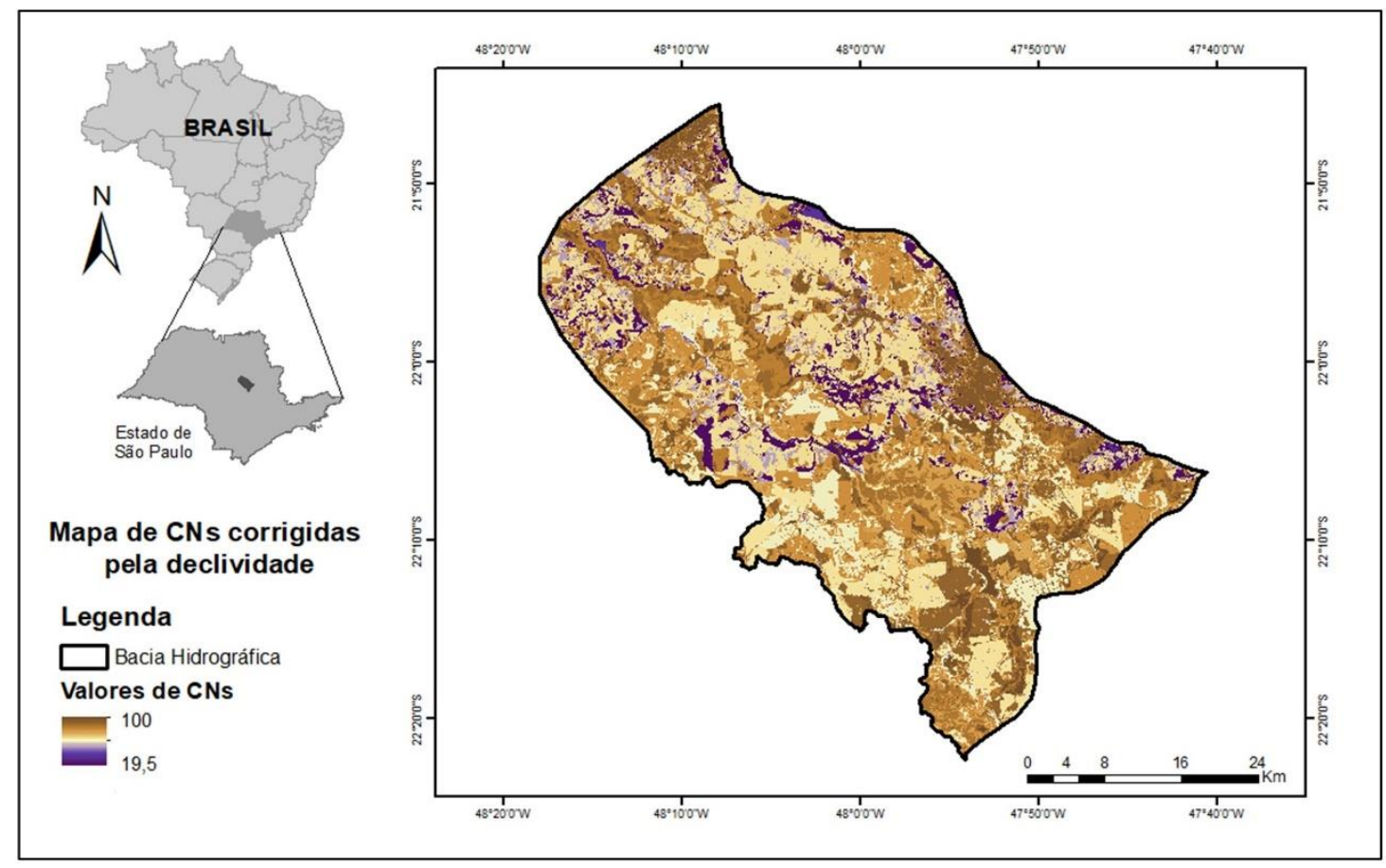

Fonte: Os autores (2020). 
Os hidrogramas gerados pelo modelo hidrológico SCS-CN para os dois eventos selecionados referemse ao exutório da bacia, sendo que na mesma célula encontra-se a estação fluviométrica. Para facilitar a comparação da propagação do escoamento resultante do filtro digital e do escoamento gerado pelo modelo, ambos os gráficos foram plotados sobrepostos, na mesma escala em $\left(\mathrm{m}^{3} / \mathrm{s}\right)$ e em duração de dias (24 horas). A Figura 7 apresenta os acumulados totais para todos os dias do evento 1 e ao hidrograma gerado pelo modelo, em relação ao hidrograma observado pelo filtro, abrangendo os dias 9 a 23 de janeiro.

Figura 7 - Acumulados totais e hidrograma gerado pelo modelo hidrológico referente ao Evento 1 (9 a 23 de janeiro de 2013).

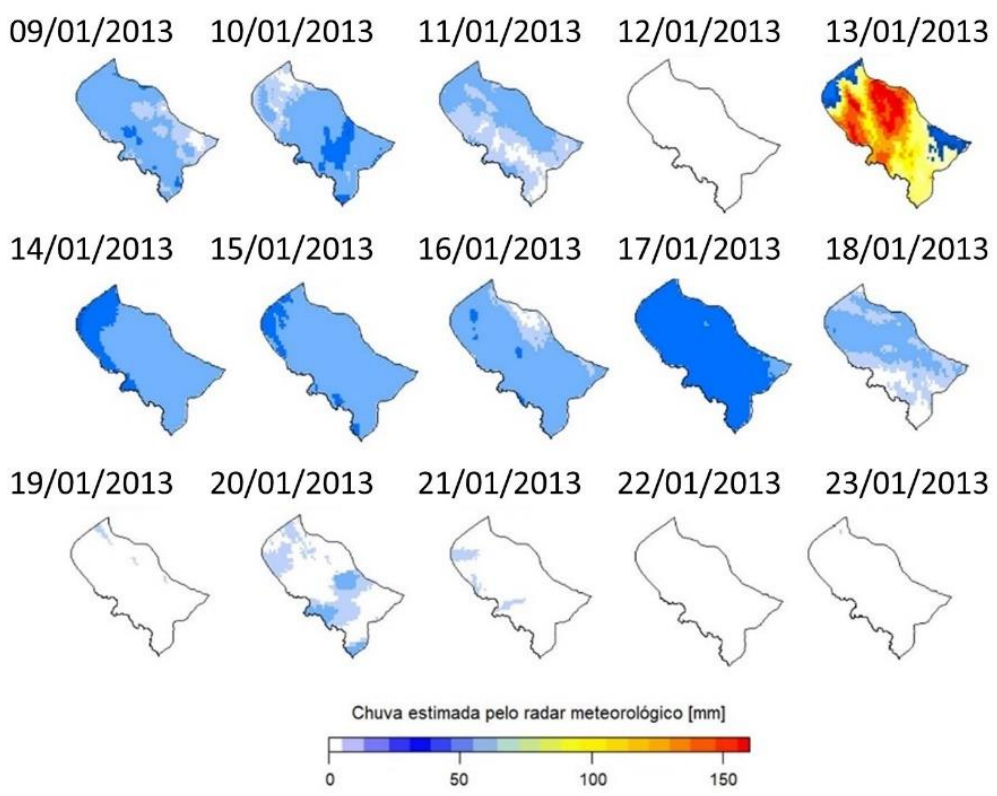

Evento 1 - (9 a 23 de janeiro de 2013)

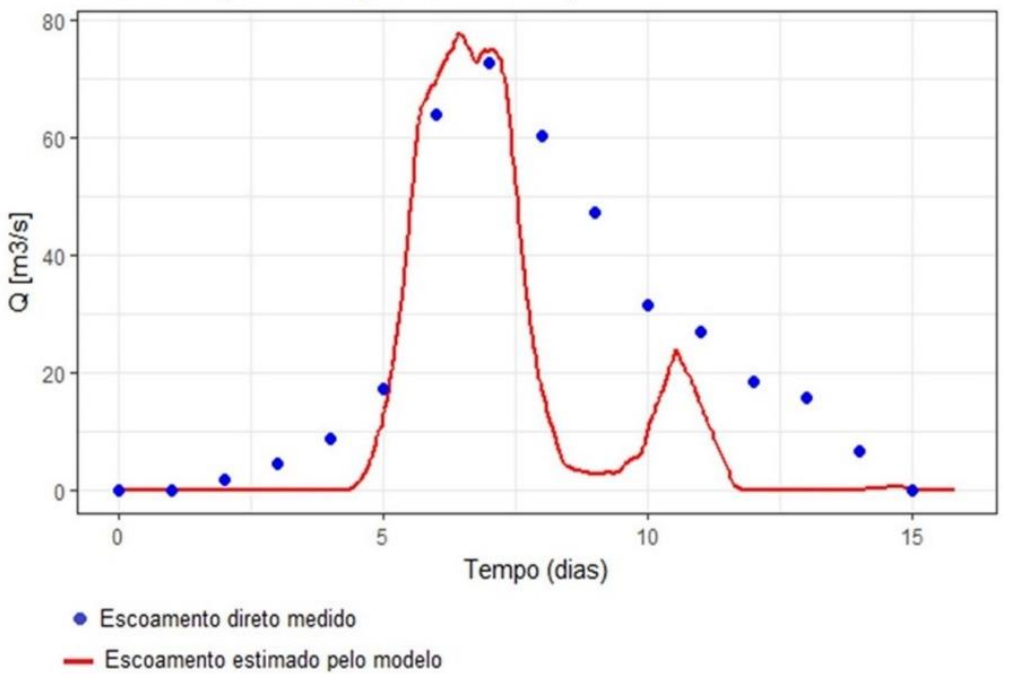

Fonte: Os autores (2020).

O hidrograma referente ao evento 1 foi calibrado com o $\lambda$ de 0,19 . Esse valor foi ajustado de acordo com o escoamento superficial extraído do filtro digital. No primeiro evento é nítido a variação do tempo de base em função da condição AMC. Para os dias 13 a 18 de janeiro com condição AMC 3 predominante, o tempo de base é menor do que para o restante dos dias que possuem condição AMC 1 ou AMC 2. Por isso o escoamento superficial do modelo decai mais abruptamente em relação ao escoamento medido. Gamage, Hewa e Beecham (2015) demonstraram que de fato a umidade antecedente do solo tem um papel importante na quantificação das perdas por infiltração no modelo hidrológico SCS-CN. Dessa forma, o hidrograma referente ao modelo hidrológico é mais sensível para perdas relacionadas a umidade antecedente do solo.

O hidrograma referente ao evento 2 (Figura 8) também foi calibrado com o $\lambda$ de 0,19 , apresentando 
dois picos bem próximos, em $12 \mathrm{~m} 3 / \mathrm{s}$ e $20,2 \mathrm{~m} / \mathrm{s}$ respectivamente. Os picos foram inferiores se comparados ao evento 1, no entanto, o hidrograma reproduziu os picos associados aos máximos de precipitação ocorrida no quinto e nono dia, apesar de não reproduzir o armazenamento de água no solo. Ao analisar a distribuição da precipitação na bacia para esse evento, observou-se que a chuva mais intensa se concentrou na cabeceira da bacia (dia 7 de fevereiro). Viglione et al. (2010a) mostraram que a chuva que se desloca da cabeceira para o exutório pode produzir um pico maior de escoamento superficial em um menor tempo de pico, o que explicaria o segundo pico do hidrograma do evento 2. Assim, não importa qual for a variabilidade da chuva em uma bacia, o hidrograma resultante sempre terá a mesma forma, porém com magnitudes diferenciadas que dependem do volume total de chuva efetiva produzido em um evento.

Figura 8 - Acumulados totais e hidrograma gerado pelo modelo hidrológico referente ao Evento 2 (4 a 14 de fevereiro de 2013).

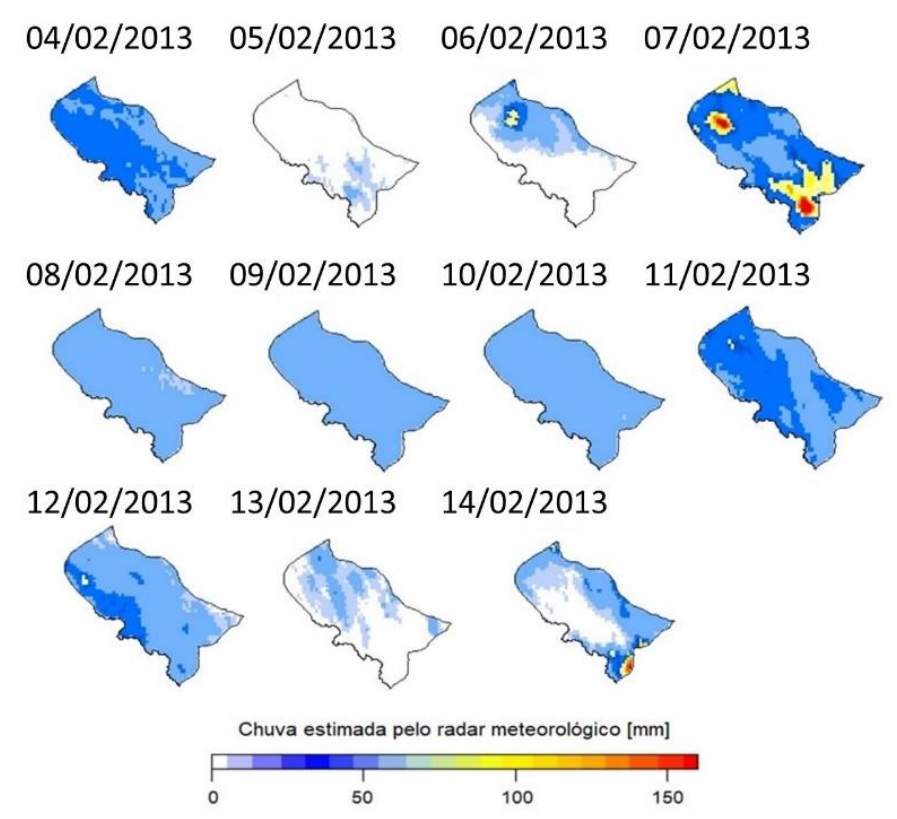

Evento 2 - (4 a 14 de fevereiro de 2013)

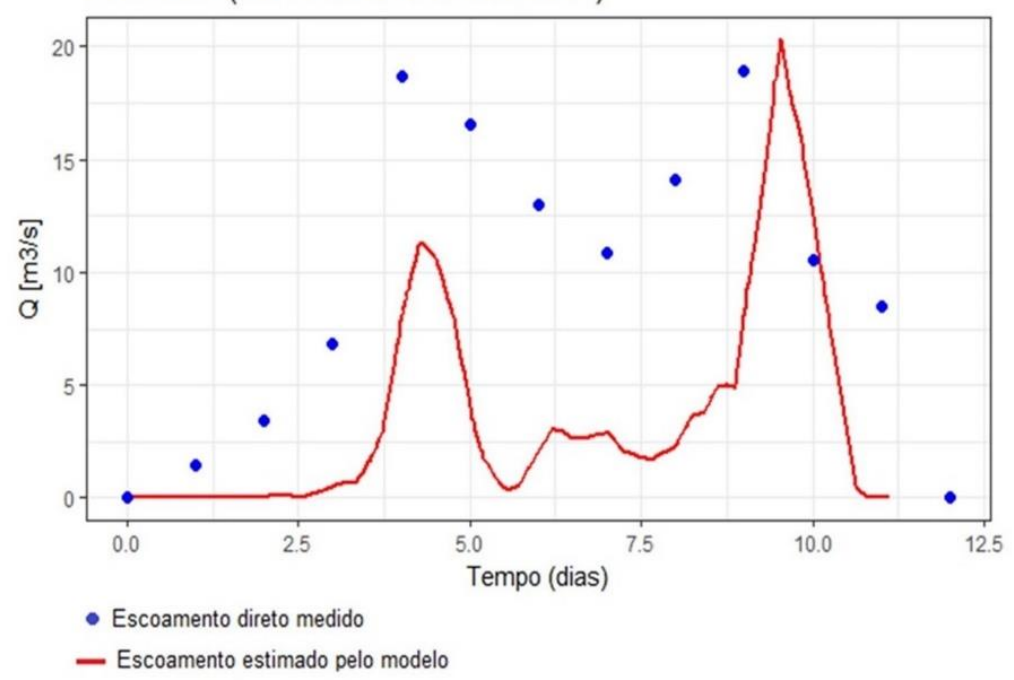

Fonte: Os autores (2020).

Há muita controversa sobre o valor de $\lambda$ mais representativo para o modelo SCS-CN na literatura. Woodward et al. (2003) determinaram a constante $\lambda$ com dados de 307 bacias e um total de 28301 eventos de chuva nos EUA. Os resultados confirmam que a constante $\lambda$ varia em função da bacia e da intensidade da precipitação. De acordo com a análise dos autores, a média encontrada para a constante foi de 0,0476. Porém, Mishra e Singh (2004) avaliaram o impacto da constante $\lambda$ no modelo SCS-CN e concluíram que o aumento da constante diminui a eficiência do modelo. 
Viglione et al. (2010b) evidenciaram que a variabilidade espaço-temporal da chuva, de fato tem um papel importante na geração e propagação de escoamento. Entretanto, há controversas como o estudo de Corradini e Singh (1985) que constataram que o escoamento superficial é insensível à variabilidade espaçotemporal da chuva efetiva, devido ao processo de suavização imposto pelos mecanismos de propagação.

Os resultados foram satisfatórios em relação a propagação do escoamento superficial gerada pelo modelo hidrológico SCS-CN. Neste trabalho, buscou-se implementar um modelo hidrológico específico para a bacia do Rio Jacaré Guaçu. Dessa forma, o parâmetro $\lambda$ foi calibrado de acordo com cada evento. Porém, é preciso levar em consideração alguns fatores de incerteza no processo de implementação do modelo hidrológico. Os valores tabelados da $C N$ não foram calibrados o que pode adicionar ainda mais incerteza na estimativa da chuva efetiva e consequentemente na propagação do escoamento. Outro fator de incerteza é o processo de reamostragem dos dados de entrada para o tamanho da célula do radar. Esse processo pode suavizar a variabilidade introduzida na chuva pelo uso e cobertura da terra e tipos de solo, que apresentam uma variabilidade espacial muito maior que $1 \mathrm{~km}$ do tamanho da célula do radar. Além disso, devido à dificuldade de se calcular a velocidade média do escoamento superficial para cada trecho da rede de drenagem, o coeficiente $k$ foi calibrado em 0,7 para ambos os eventos, pois foi o valor que apresentou a curva mais suavizada do hidrograma. Esse valor varia de acordo com a rugosidade do canal e com o raio hidráulico, portanto, utilizar apenas um único valor para todo o trecho está supondo que o escoamento superficial apresenta uma velocidade constante.

\section{CONCLUSÕES}

A integração com os dados pluviométricos manteve a estrutura espacial do radar e converteu a taxa de precipitação para os valores registrados na rede pluviométrica. Desta forma, acredita-se que o campo resultante da integração é mais realístico que medições e estimativas obtidas isoladamente. Isso se deve ao fato de que, embora sensores remotos ainda não possuam uma boa acurácia na determinação do valor acumulado de chuva tal como o pluviômetro, alguns sensores apresentam uma alta resolução espacial, como nesse caso de $1 \mathrm{~km} \mathrm{x}$ $1 \mathrm{~km}$. Nesse trabalho, o modelo hidrológico SCS-CN não pode ser generalizado aos eventos analisados, pois o seu comportamento não respondeu muito bem aos mesmos valores de calibração para todos os eventos. Por isso, houve a necessidade de se analisar cada evento separadamente e atribuir valores específicos aos parâmetros.

É preciso ressaltar que alguns fatores de incerteza foram levados em consideração no processo de implementação do modelo hidrológico. Um dos fatores é de que a falta de calibração de parâmetros do modelo SCS-CN, como os valores tabelados da CN, pode ter produzido alguns valores espúrios de chuva efetiva e, consequentemente, isso pode ter interferido nos valores de propagação do escoamento superficial. É possível também que o processo de reamostragem dos dados de entrada do modelo para o tamanho da célula do radar pode ter suavizado a variabilidade espacial inserida pelo tipo de solo e uso e cobertura da terra.

Além disso, devido à dificuldade de se calcular a velocidade média do escoamento superficial para cada trecho da rede de drenagem, o coeficiente $k$ foi calibrado em 0,7 , pois foi o valor que apresentou a curva mais suavizada do hidrograma, para ambos os eventos e em todos os trechos da rede de drenagem. Esse valor varia de acordo com a rugosidade do canal e com o raio hidráulico, portanto, utilizar apenas um único valor para todo o trecho está supondo que o escoamento superficial apresenta uma velocidade constante.

Contudo, o uso de dados de radar meteorológico mostrou-se uma importante ferramenta para o monitoramento e previsão hidrometeorológica. Vale ressaltar que a metodologia apresentada nesse estudo pode sofrer alterações se aplicada em uma região mais próxima ou mais distante do radar utilizado. Para o futuro, são necessárias novas avaliações para diferentes regimes de chuva e novos modelos de previsão devem ser inseridos para aumentar a capacidade de identificação de fenômenos nas diversas escalas de tempo e espaço, e assim, se tornar uma importante ferramenta para os tomadores de decisão no auxílio do gerenciamento e controle de enchentes. 


\section{Agradecimentos}

Os autores agradecem a Coordenação de Aperfeiçoamento de Pessoal de Nível Superior - Brasil (CAPES) - Código de referência (PROEX - 0487) pelo apoio ao financiamento da presente pesquisa e ao Instituto de Pesquisas Meteorológicas de Bauru (IPMet/UNESP) pelo fornecimento dos dados de radar meteorológico.

\section{Contribuição dos Autores}

B. H. MIGUEL e C. D. RENNÓ atuaram conjuntamente nas etapas de conceptualização, curadoria dos dados, análise formal, investigação, metodologia, recursos, software e validação. B. H. MIGUEL foi responsável pela visualização e redação - minuta inicial. C. D. RENNÓ foi responsável pela aquisição de financiamento, administração do projeto, supervisão e redação - revisão e edição.

\section{Conflitos de Interesse}

Os autores declaram que não há conflito de interesse.

\section{Referências}

AGÊNCIA NACIONAL DE ÁGUAS (ANA). Medição de descarga líquida em grandes rios: Manual Técnico. 2.ed. Brasília, DF: ANA - Superintendência de Gestão da Rede Hidrometeorológica, 2014.

AMERICAN SOCIETY OF CIVIL ENGINEERS (ASCE). Hydrology handbook. 2 ed. New York, USA: ASCE, 1996.

ARNOLD, J. G.; WILLIAMS, J. R. SWRRB - A watershed scale model for soil and water resources management. Computer Models of Watershed Hydrology, VP SING. 1995.

BEVEN, K. J. Rainfall-Runoff modelling: the primer. 2 ed. Lancaster, UK: John Wiley \& Sons, 2012.

CABRAL, S. L.; SAKURAGI, J.; SILVEIRA, C. D. Incertezas e erros na estimativa de vazões usando modelagem hidrológica e precipitação por RADAR. Revista Ambiente \& Água, v. 12, n. 1, p. 57-70, 2017. DOI.: 10.4136/ambi-agua.1924.

CHOW, V. T.; MAIDMENT, D. R.; MAYS, L. W. Applied Hydrology. New York: McGrawhill International Editions: Civil Engineering Series, 1998.

COLE, S. J.; MOORE, R. J. Hydrological modelling using rain gauge and radarbased estimators of areal rainfall. Journal of Hydrology, v. 358, n. 3-4, 159-181, 2008. DOI.: 10.1016/j.hydrol.2008.05.025.

CORRADINI, C.; SINGH, V. P. Effect of spatial variability of effective rainfall on direct runoff by a geomorphologic approach. Journal of Hydrology, v. 81, p. 27-43, 1985. DOI.: 10.1016/00221694(85)90165-9.

ECKHARDT, K. How to construct recursive digital filters for baseflow separation. Hydrological Processes, v. 19, n. 2, p. 507-515, 2005. DOI.: 10.1002/hyp.5675.

EMMANUEL, I.; ANDRIEU, H.; LEBLOIS, E.; JANEY, N.; PAYRASTRE, O. Influence of rainfall spatial variability on rainfall-runoff modeling: benefit of a simulation approach? Journal of Hydrology, v. 531, p. 337-348, 2015. DOI.: 10.1016/j.hydrol.2015.04.058.

FAN, F. M.; COLLISCHONN, W. Integração do modelo MGB-IPH com sistema de informação geográfica. Revista Brasileira de Recursos Hídricos, v. 19, n. 1, p. 243-254, 2014. DOI.: 10.21168/rbrh.v19n1.p243-254.

FAN, F. M.; RAMOS, M. H.; COLLISCHONN, W. Sobre o uso de previsões hidrológicas probabilísticas para tomada de decisão. Revista Brasileira de Recursos Hídricos, v. 20, n. 4, p. 914-926, 2015. DOI.: 10.21168/rbrh.v20n4.p914-926.

GAMAGE, S. H. P. W.; HEWA, G. A.; BEECHAM, S. Modelling hydrological losses for varying rainfall and 
moisture conditions in South Australian catchments. Journal of Hydrology: Regional Studies, v. 4, p. 121, 2015. DOI.: 10.1016/j.ejrh.2015.04.005.

INSTITUTO DE PESQUISAS METEOROLÓGICAS DE BAURU (IPMET). Montagem do CAPPI. Disponível em <https://www.ipmetradar.com.br/2saibaRadar.php>, Acesso em: 12 jun 2020.

MARSHALL, J. S.; PALMER, W. M. K. The distributions of raindrops with size. Journal of Meteorology, v. 5, p. 165-6, 1948. DOI.: 10.1175/1520-0469(1948)005<TDORWS>2.0.CO;2.

MIGUEL, B. H. Uso de dados de radar meteorológico em modelo hidrológico SCS-CN para estimativa do escoamento superficial. 133 f. Dissertação (Mestrado em Sensoriamento Remoto) - Instituto Nacional de Pesquisas Espaciais, INPE, São José dos Campos, 2018.

MISHRA, S. K.; SINGH, V. P. Long-term hydrological simulation based on the Soil Conservation Service curve number. Hydrological Processes, v. 18, n. 7, p. 1291-1313, 2004. DOI.: 10.1002/hyp.1344.

MISHRA, V.; AAADHAR, S.; SHAH, H.; KUMAR, R.; PATTANAIK, D. R.; TIWARI, A. D. The Kerala flood of 2018: combined impact of extreme rainfall and reservoir storage. Hydrology and Earth System Sciences Discussions, p. 1-13, 2018. DOI.: 10.5194/hess-2018-480

OLIVEIRA, J. B.; CAMARGO, M. N.; ROSSI, M.; CALDERANO FILHO, B. Mapa pedológico do Estado de São Paulo: legenda expandida. Campinas: Instituto Agronômico; Rio de janeiro: Embrapa-Solos, 1999. 64 p. Escala: 1.500 .000$.

PEREIRA, L. M. Modelagem hidrológica dinâmica distribuída para estimativa do escoamento superficial em uma microbacia urbana. 2008. 90 p. (INPE-15679-TDI/1453). Dissertação (Mestrado em Sensoriamento Remoto) - Instituto Nacional de Pesquisas Espaciais (INPE), São José dos Campos, 2009.

POTDAR, S. S.; KULKARNI, S.; PATIL, P.; PAWAR, R. P.; JAKHALEKAR, V. V.; NADE, D. P. The longterm trend analysis of rainfall data from 1901 to 2015 for Maharashtra and Goa region from India. International Journal of Water, v. 13, n. 3, p. 293-309, 2019. DOI.: 10.1504/IJW.2019.101340.

PRICE, K.; PURUCKER, S. T.; KRAEMER, S. R.; BABENDREIER, J. E.; KNIGHTES, C. D. Comparison of radar and gauge precipitation data in watershed models across varying spatial and temporal scales. Hydrological Processes, v. 28, n. 9, p. 3505-3520, 2014. DOI.: 10.1002/hyp.9890.

RAGHAVAN, S. Radar meteorology. Berlin: Springer Science \& Business Media, 2013.

RENNÓ, C. D.; NOBRE, A. D.; CUARTAS, L. A.; SOARES, J. V.; HODNETT, M. G.; TOMASELLA, J.; WATERLOO, M. J. HAND, a new terrain descriptor using SRTM-DEM: Mapping terra-firme rainforest environments in Amazonia. Remote Sensing of Environment, v. 112, p. 3469-3481, 2008. DOI.: 10.1016/j.rse.2008.03.018.

ROSIM, S.; OLIVEIRA, J. R. F.; JARDIM, A. C.; NAMIKAWA, L. M.; RENNÓ, C.D. TerraHidro: a distributed hydrology modelling system with high quality drainage extraction. In: INTERNATIONAL CONFERENCE ON ADVANCED GEOGRAPHIC INFORMATION SYSTEMS, APPLICATIONS, AND SERVICES, 5., (IARIA) 2013, Nice, França. Proceedings... Nice: 2013. p. 161-167.

SARTORI, A; GENOVEZ, A. M; LOMBARDI NETO, F. Classificação hidrológica de solos brasileiros para a estimativa da chuva excedente com o método do Serviço de Conservação do Solo dos Estados Unidos parte II: aplicação. Revista Brasileira de Recursos Hídricos, v. 10, n. 4, p. 05-18, 2005. DOI.: 10.21168/rbrh.v10n4.p5-18.

SCS. National Engineering Handbook, Hydrology, Section 4, Soil Conservation Service, US Department of Agriculture, Washington DC, 1956.

THIESSEN, A. H. Precipitation averages for large areas. Monthly weather review, v. 39, n. 7, p. 1082-1089, 1911. DOI.: 10.1175/1520-0493(1911)39<1082b:PAFLA>2.0CO;2.

THORNDAHL, S.; EINFALT, T.; WILLEMS, P.; NIELSEN, J. E.; VELDHUIS, M. C.; ARNBJERGNIELSEN, K.; MOLNAR, P. Weather radar rainfall data in urban hydrology. Hydrology and Earth System Sciences, v. 21, n. 3, p. 1359-1380, 2017. DOI.: 10.5194/hess-21-1359-2017.

TSO, B.; MATHER, P. M. Classification methods for remotely sensed data. New York: Taylor \& Francis, 
2009.

TUCCI, C. E. M. (Org.). Hidrologia: ciência e aplicação. 3.ed. Porto Alegre: Ed. Universidade/ UFRGS: ABRH, 2002.

UNITED STATES DEPARTMENT OF AGRICULTURE - SOIL CONSERVATION SERVICE (USDASCS). Urban hydrology for small watersheds: TR55. Washington, USA: USDA-SCS, 1986.

VIGLIONE, A.; CHIRICO, G. B.; WOODS, R.; BLÖSCHL, G. Generalized synthesis of space-time variability in flood responded: an analytical framework. Journal of Hydrology, v. 394, p. 198-212, 2010 a. DOI.: 10.1016/j.hydrol.2010.05.047.

VIGLIONE, A.; CHIRICO, G. B.; KOMMA, J.; WOODS, R.; BORGA, M.; BLÖSCHL, G. Quantifying space-time dynamics of flood event types. Journal of Hydrology, v. 394, p. 213-229, 2010b. DOI.: 10.1016/j.hydrol.2010.05.041.

WOODWARD, D. E.; HAWKINS, R. H.; JIANG, R.; HJELMFELT, A. T.; VAN MULLEM, J. A.; QUAN, Q. D. Runoff curve number method: examination of the initial abstraction ratio. In: WORLD WATER AND ENVIRONMENTAL RESOURCES CONGRESS, 2003, Philadelphia. Proceedings... American Society of Civil Engineers (ASCE) Publications, 2003.

ZHANG, M.; LIU, N.; HARPER, R.; LI, Q.; LIU, K.; WEI, X.; LIU, S. A global review on hydrological responses to forest change across multiple spatial scales: Importance of scale, climate, forest type and hydrological regime. Journal of Hydrology, v. 546, p. 44-59, 2017. DOI.: 10.1016/j.hydrol.2016.12.040.

\section{Biografia do autor principal}

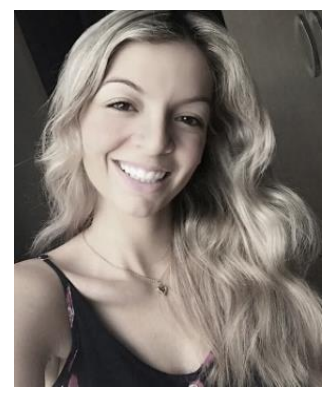

Bárbara Hass Miguel, brasileira, nascida em Bauru-SP, 1991. Possui Graduação em Gestão e Análise Ambiental pela Universidade Federal de São Carlos (UFSCar) e Mestrado em Sensoriamento Remoto pelo Instituto Nacional de Pesquisas Espaciais (INPE). Atualmente é Doutoranda em Geociências Aplicadas e Geodinâmica na Universidade de Brasília (UnB). No doutorado está desenvolvendo um projeto junto ao Centro Gestor e Operacional do Sistema de Proteção a Amazônia (Censipam/MD) para a análise de áreas de regeneração florestal na Amazônia utilizando dados de Radar de Abertura Sintética (SAR). Interesses de pesquisa: Geoprocessamento, Sensoriamento Remoto, Hidrologia, Processamento de imagens e uso de dados SAR. 